\title{
Erratum to: Parallelization Strategies for Spatial Agent-Based Models
}

\author{
Nuno Fachada ${ }^{1}$ (D) Vitor V. Lopes ${ }^{2}$. \\ Rui C. Martins ${ }^{3}$ - Agostinho C. Rosa ${ }^{1}$
}

Published online: 2 May 2017

(C) Springer Science+Business Media New York 2017

\section{Erratum to: Int J Parallel Prog (2017) 45:449-481 DOI 10.1007/s10766-015-0399-9}

The original version of this article unfortunately contained a mistake. The presentation of Table 3 was incorrect. The corrected (Table 3) is given below.

The online version of the original article can be found under doi:10.1007/s10766-015-0399-9.

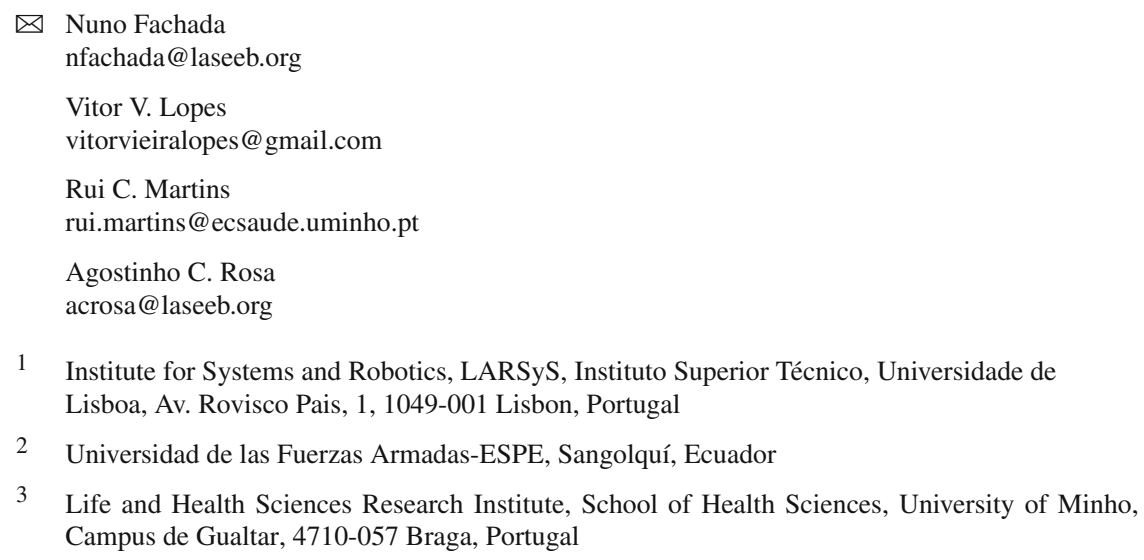

3 Life and Health Sciences Research Institute, School of Health Sciences, University of Minho, Campus de Gualtar, 4710-057 Braga, Portugal 
Table 3 A selection of initial model sizes

\begin{tabular}{lcrr}
\hline Size & $x_{\text {env }} \times y_{\text {env }}$ & $P_{0}^{s}$ & $P_{0}^{w}$ \\
\hline 100 & $100 \times 100$ & 400 & 200 \\
200 & $200 \times 200$ & 1600 & 800 \\
400 & $400 \times 400$ & 6400 & 3200 \\
800 & $800 \times 800$ & 25,600 & 12,800 \\
1600 & $1600 \times 1600$ & 102,400 & 51,200 \\
3200 & $3200 \times 3200$ & 409,600 & 204,800 \\
6400 & $6400 \times 6400$ & $1,638,400$ & 819,200 \\
12,800 & $12,800 \times 12,800$ & $6,553,600$ & $3,276,800$ \\
$\vdots$ & $\vdots$ & $\vdots$ & $\vdots$ \\
\hline
\end{tabular}

Sizes above the dashed line are studied in detail in this work 